\title{
Dynamic smile reanimation in facial nerve palsy
}

\author{
Krishnakumar Krishnan Santha', Subin Joseph², Sameer Latheef ${ }^{2}$, Saju Narayanan', \\ Santhy Mohanachandran Nair², Bibilash Babu ${ }^{1}$, Anand Sivadasan², Srivatsa Manjunath Shet ${ }^{2}$, \\ Rajesh Vardhan Pydi ${ }^{2}$, Ajit Pati ${ }^{1}$, Srikant Aruna Samantaray ${ }^{2}$ \\ ${ }^{I}$ Department of Plastic and Reconstructive Surgery, Aster MIMS Hospital, \\ ${ }^{2}$ Department of Plastic, Reconstructive and Burns Surgery, Baby Memorial Hospital, Kozhikode, India
}

\begin{abstract}
J Korean Assoc Oral Maxillofac Surg 2020;46:143-149)
Objectives: Long-term facial paralysis results in degeneration of the distal nerve segment and atrophy of the supplied muscles. Options for these patients include free muscle transfer, temporalis myoplasty, and botulinum toxin injections for smile reanimation. In this study we aimed to evaluate the subjective and objective outcomes of these procedures.

Materials and Methods: In our study, we retrospectively analyzed smile symmetry in patients with facial palsy $(\mathrm{n}=8)$ who underwent facial reanimation procedures.

Results: Subjective analysis showed high satisfaction in seven out of eight patients. Objective analysis showed statistically significant improvement postoperatively in both vertical and horizontal smile symmetry at rest and during maximum smile $(P<0.001)$.

Conclusion: Choosing the ideal procedure for the patients is the most critical aspect for facial reanimation. Though free muscle transfer is considered gold standard procedure, temporalis myoplasty also gives satisfactory results. Residual synkinesis which can lead to disturbing aesthetic deformity can be effectively treated with botulinum toxin.
\end{abstract}

Key words: Facial nerve, Free tissue flaps, Smiling, Temporal muscle, Botulinum toxins

[paper submitted 2018. 12. 15 / revised 2019. 3. 7 / accepted 2019. 3. 18]

\section{Introduction}

The facial nerve is the nerve associated with facial expression — both voluntary and emotional. Facial nerve paralysis can produce not only aesthetic deficits but also functional and emotional disturbances ${ }^{1}$ as any attempt to smile aggravates the facial asymmetry ${ }^{2}$. In long-standing facial palsy, the distal nerve segment degenerates over time and the muscles atrophy $^{3}$. Re-innervation of the muscle must be achieved within 18 to 24 months of initial injury. Hence in patients that present late with ongoing facial palsy of more than two years,

\section{Subin Joseph}

Department of Plastic, Reconstructive and Burns Surgery, Baby Memorial Hospital, Indira Gandhi Road, Kozhikode 673004, India

TEL: +91-9446985820

E-mail:subinjozf@gmail.com

ORCID: https://orcid.org/0000-0002-4079-5499

(c) This is an open-access article distributed under the terms of the Creative Commons Attribution Non-Commercial License (http://creativecommons.org/ licenses/by-nc/4.0/), which permits unrestricted non-commercial use, distribution, and reproduction in any medium, provided the original work is properly cited.

Copyright (C) 2020 The Korean Association of Oral and Maxillofacial Surgeons. All rights reserved. facial reanimation procedures are performed to restore the facial symmetry, resting tone and voluntary movement during smile ${ }^{4}$. Free muscle transfer represents the gold standard treatment for long-standing facial paralysis ${ }^{5}$. However, other options such as temporalis myoplasty ${ }^{6}$ and botulinum toxin injection ${ }^{7}$ are also widely practiced. In this study we aimed to evaluate the subjective and objective outcomes of these procedures.

\section{Materials and Methods}

The study was conducted in the Department of Plastic, Reconstructive and Burns Surgery of Baby Memorial Hospital (Kozhikode, India) after approval from the Institutional Ethics Committee (No. BMH/IEC/PS/09/2020). Eight patients with lower motor neuron (LMN) facial palsy, irrespective of the etiology, age and sex, who underwent facial reanimation procedures from 2006 to 2016 were retrospectively analyzed. Out of the eight subjects, six patients had undergone temporalis myoplasty, while one patient underwent a free gracilis muscle transfer and one underwent a botulinum toxin injec- 
tion. Subjective outcome assessment was done as per the questionnaire (Table 1) described by Sassoon et al. ${ }^{8}$ with few modifications.

Objective assessment was conducted using the pre- and postoperative photographs at rest and during smile. The vertical and horizontal smile symmetry were assessed for each patient. Photographs were initially standardized by comparing white to white iris diameter against the standard human reference value ${ }^{9}$ of $11.7 \mathrm{~mm}$ to obtain a multiplication factor $^{10}$ using Adobe Photoshop CC v20 (Adobe, San Jose, CA, USA). An inter-pupillary line (IPL) was drawn and from the midpoint of the IPL, a perpendicular line was dropped down

Table 1. Subjective assessment questionnaire

\begin{tabular}{ccl}
\hline No. & \multicolumn{2}{c}{ Parameter assessed } \\
\hline 1 & $\begin{array}{c}\text { How concerned were you } \\
\text { before surgery? }\end{array}$ & $\begin{array}{l}\text { Highly concerned } \\
\text { Fairly concerned }\end{array}$ \\
2 & $\begin{array}{c}\text { How satisfied are you after } \\
\text { surgery? }\end{array}$ & $\begin{array}{l}\text { Highly satisfied } \\
\text { Fairly satisfied }\end{array}$ \\
& Unsatisfied \\
3 & How much improvement in \\
& facial symmetry have you & Greatly improved \\
& noticed at rest? & Slightly improved \\
4 & $\begin{array}{c}\text { How much improvement in } \\
\text { facial symmetry have you } \\
\text { noticed during smile? }\end{array}$ & Greatly improved \\
& Slightly improved \\
5 & Will you recommend this & Yes \\
& to similar patients? & No \\
\hline
\end{tabular}

Krishnakumar Krishnan Santha et al: Dynamic smile reanimation in facial nerve palsy. $J$ Korean Assoc Oral Maxillofac Surg 2020 to the chin point. Another line was drawn parallel to the vertical line joining the lowest point of cupid's bow and IPL. The delta horizontal $(\mathrm{DH})$ value was calculated as the distance between these two vertical lines.(Fig. 1) Separate horizontal lines were drawn to connect the commissures to the midline vertical. The distance between these two horizontal lines was calculated as the delta vertical (DV). Finally, the DH and DV were standardized as a real scale using multiplication factors. Statistical analysis of the quantitative data was performed using the IBM SPSS Statistics software v25 (IBM Corp., Armonk, NY, USA). Means were compared using a paired ttest for both $\mathrm{DH}$ and $\mathrm{DV}$ at rest and during maximum smile ${ }^{11}$.

\section{Operative technique}

\section{1) Free muscle transfer}

After informed consent, the patient was counseled about realistic expectations and achievable goals. The surgery was done in a single stage. A parotidectomy incision (lazy S) with extension to the submandibular region was used to expose the paralyzed side of the face. The skin flap over the parotidmasseteric fascia was dissected until the orbicularis muscle of the lips on the affected site was visualized. Another incision was made on the normal side, $1 \mathrm{~cm}$ above and parallel to the nasolabial crease and facial nerve branches were identified. On stimulation, the branch which produced upward and
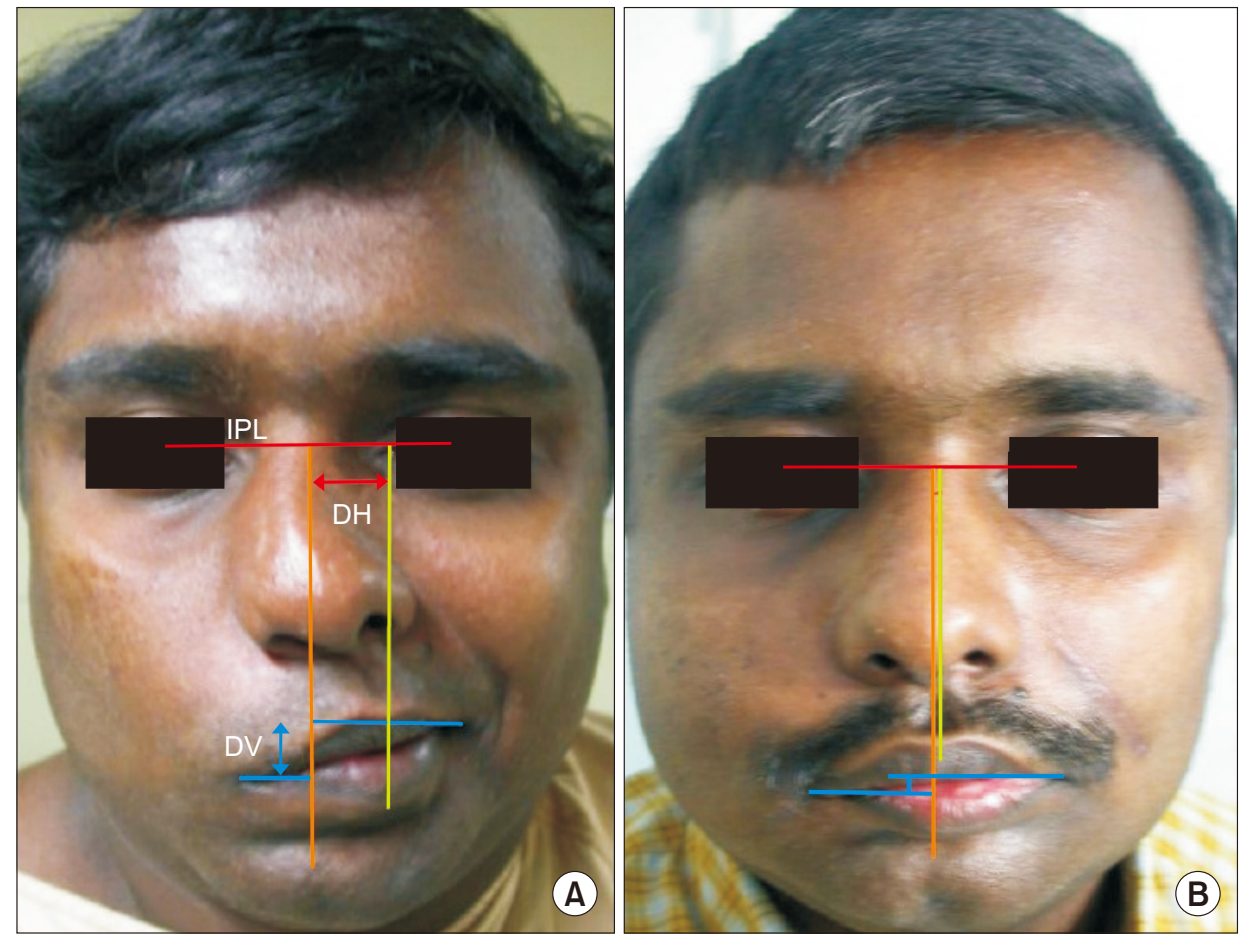

Fig. 1. Objective assessments of preoperative (A) and postoperative (B) photographs. (IPL: inter pupillary line, $\mathrm{DH}$ : delta horizontal left right arrow, DV: delta vertical up down arrow)

Krishnakumar Krishnan Santha et al: Dynamic smile reanimation in facial nerve palsy. $J$ Korean Assoc Oral Maxillofac Surg 2020 


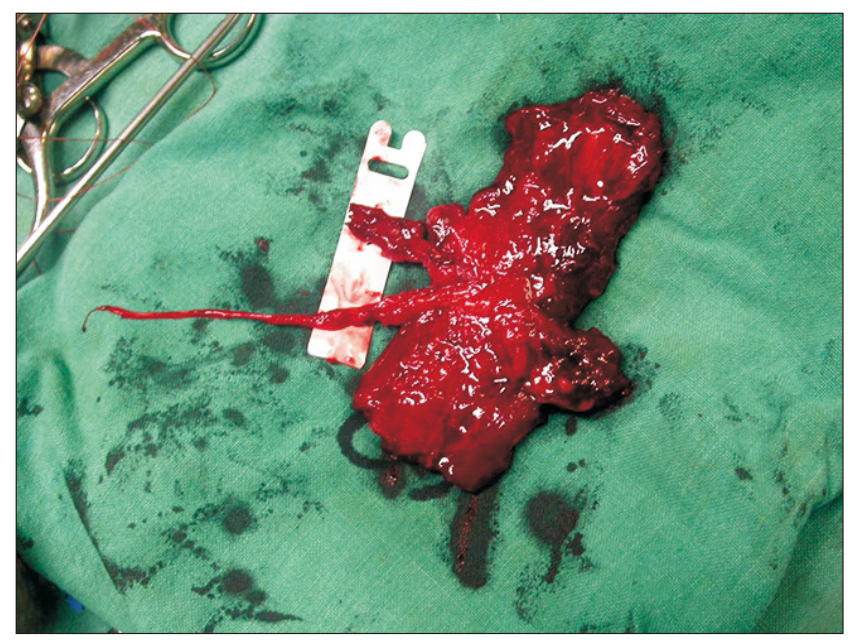

Fig. 2. Harvested free gracilis muscle with neurovascular pedicle. Krishnakumar Krishnan Santha et al: Dynamic smile reanimation in facial nerve palsy. $J$ Korean Assoc Oral Maxillofac Surg 2020

lateral movement of the angle of mouth and upper lip, was selected, which is typical for the branches of buccal division of the facial nerve. The anterior one-third of the gracilis muscle and the required muscle length were marked before the muscle was divided. The free gracilis muscle flap was harvested with the neurovascular pedicle in such a way that, most of the muscle was distal to the pedicle.(Fig. 2) The flap was positioned over the face so that the motor nerve could reach the contralateral side after tunneling through the upper lip. The motor nerve was coapted to the selected facial nerve branch and the vascular pedicle was anastomosed to the facial vessels. Donor and recipient site closures were performed in layers.

\section{2) Temporalis myoplasty}

An incision was made in front of the ear, extending to above the temporo-parietal region of the scalp. The temporalis muscle and deep temporal fascia were identified after elevating the skin flap above the superficial musculo-aponeurotic system of the face. A small incision was made at the angle of the mouth along the vermillion border. A tunnel was made in the subcutaneous plane between these two incisions. The mid-portion of the temporalis muscle was marked and dissected along with deep temporal fascia and pericranium. Two slips were created by splitting the deep temporal fascia overlying the muscle.(Fig. 3) The muscle and the slips were flipped over the zygomatic arch and tunneled through the subcutaneous plane to reach the oral commissure. The fascial slips were sutured to the orbicularis muscle of the upper and lower lips and the modiolus to maximum tightness. Hemo-

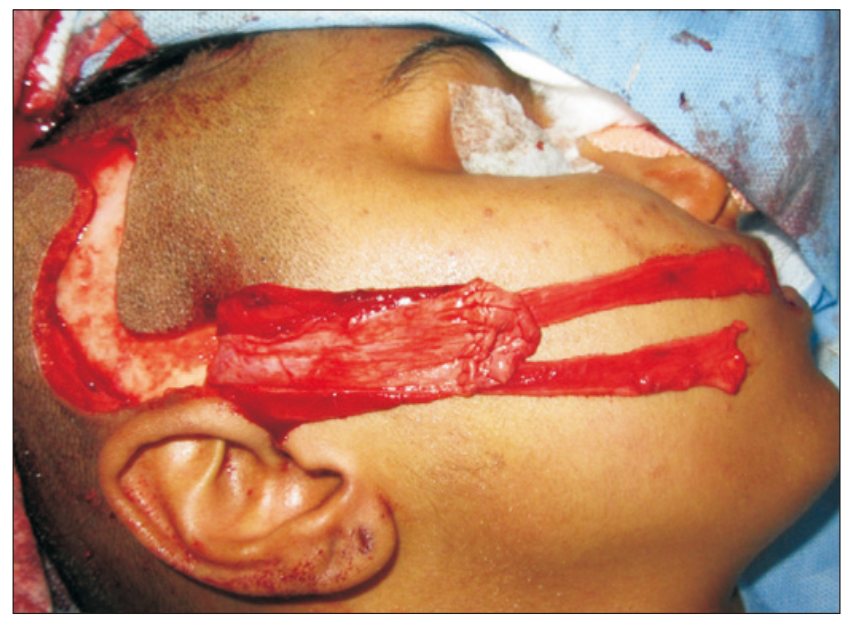

Fig. 3. Temporalis muscle with fascial slings.

Krishnakumar Krishnan Santha et al: Dynamic smile reanimation in facial nerve palsy. $J$ Korean Assoc Oral Maxillofac Surg 2020

stasis was attained and closure was completed over a suction drain.

\section{3) Botulinum toxin}

An intramuscular injection of 2 IU of botulinum toxin type B was applied to the upper lip elevators which included the zygomaticus major, zygomaticus minor, and levator anguli oris muscles.

\section{Postoperative smile therapy}

All patients who underwent temporalis myoplasty were given temporalis muscle stimulation 1 week following surgery and this was continued for 4 months. All were retrained to smile after clenching their teeth. Nerve stimulation was performed for 6 months for the free gracilis muscle transfer patients, after the cross facial nerve graft. In addition, patients were advised by a physiotherapist to complete regular massage and blowing, sucking, puffing and gargling exercises.

\section{Results}

The subject ages group ranged from 4 to 50 years with a mean age at surgery of 30 years. Out of these, five patients were males and three were females with a sex ratio of 5:3. Four patients had congenital facial palsy, one had posttraumatic facial palsy and three patients were diagnosed with idiopathic facial palsy. Five patients had facial palsy on the right side and three had palsy on the left side. All patients had more than a three year history of facial palsy. No syndromic 
Table 2. Subjective assessment results

\begin{tabular}{|c|c|c|c|}
\hline No. & Parameter assessed & & No. of patients (\%) \\
\hline \multirow[t]{2}{*}{1} & How concerned were you before surgery? & Highly concerned & $7(87.5)$ \\
\hline & & Fairly concerned & $1(12.5)$ \\
\hline \multirow[t]{3}{*}{2} & How satisfied are you after surgery? & Highly satisfied & $7(87.5)$ \\
\hline & & Fairly satisfied & $1(12.5)$ \\
\hline & & Unsatisfied & $0(0)$ \\
\hline \multirow[t]{2}{*}{3} & How much improvement in facial symmetry have you noticed at rest? & Greatly improved & $7(87.5)$ \\
\hline & & Slightly improved & $1(12.5)$ \\
\hline \multirow[t]{2}{*}{4} & How much improvement in facial symmetry have you noticed during smile? & Greatly improved & $6(75.0)$ \\
\hline & & Slightly improved & $2(25.0)$ \\
\hline \multirow[t]{2}{*}{5} & Will you recommend this to similar patients? & Yes & $8(100)$ \\
\hline & & No & $0(0)$ \\
\hline
\end{tabular}

Krishnakumar Krishnan Santha et al: Dynamic smile reanimation in facial nerve palsy. J Korean Assoc Oral Maxillofac Surg 2020

Table 3. Objective assessment results with associated $P$-value

\begin{tabular}{lllrl}
\hline & & Preoperative & Postoperative & $P$-value \\
\hline Delta vertical $(\mathrm{mm})$ & At rest & $11.29 \pm 1.38$ & $3.33 \pm 0.51$ & $<0.001$ \\
& Maximum smile & $15.39 \pm 1.92$ & $3.77 \pm 0.66$ & $<.001$ \\
Delta horizontal (mm) & At rest & $16.36 \pm 2.80$ & $1.8 \pm 0.23$ & $<0.001$ \\
& Maximum smile & $10.37 \pm 0.62$ & $3.04 \pm 0.23$ & $<0.001$ \\
\hline
\end{tabular}

Values are presented as mean \pm standard deviation.

$P$-values by paired t-test.

Krishnakumar Krishnan Santha et al: Dynamic smile reanimation in facial nerve palsy. J Korean Assoc Oral Maxillofac Surg 2020
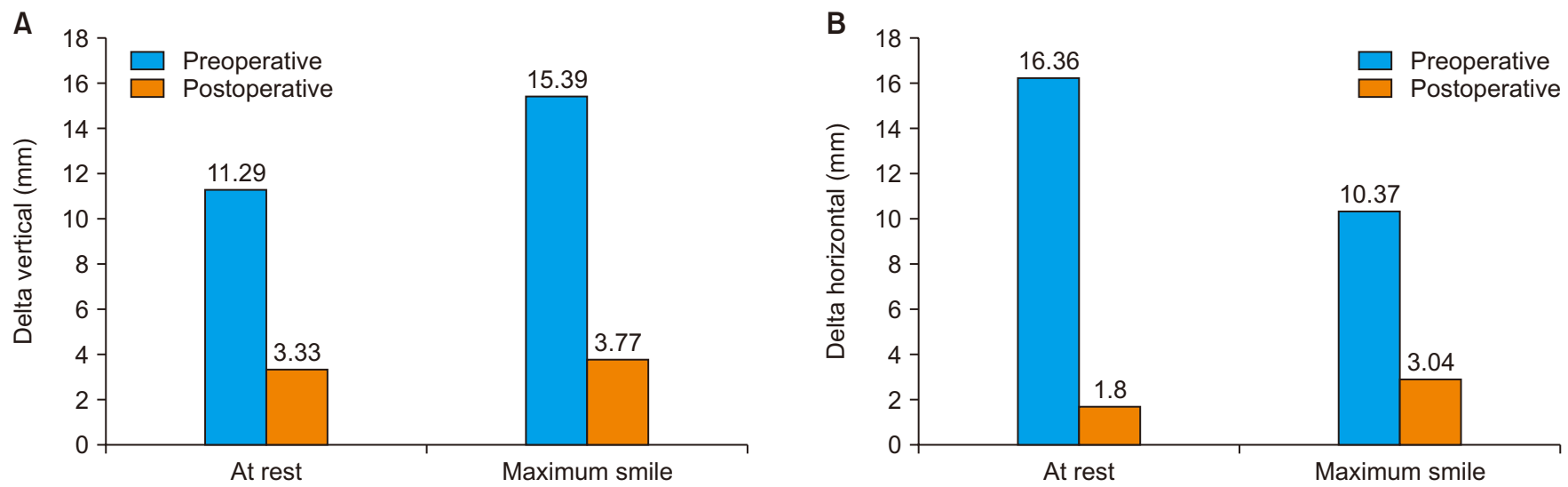

Fig. 4. Comparison of preoperative and postoperative means of delta vertical (A) and delta horizontal (B) both at rest and maximal smile. Krishnakumar Krishnan Santha et al: Dynamic smile reanimation in facial nerve palsy. J Korean Assoc Oral Maxillofac Surg 2020

associations were identified in any of the patients.

There were no serious intraoperative or postoperative complications except for facial edema following surgery. The mean hospital stay was 6 days. Table 2 shows the distribution of answers to key questions. The majority of patients were highly satisfied with the treatment modalities. Most of the patients reported great improvement in their facial symmetry both at rest and when smiling. All patients indicated that they would recommend the procedure to others with similar conditions. Objective analysis showed a statistically significant improvement in facial symmetry both at rest and during maximal smile $(P<0.001)$ as shown in Table 3. Fig. 4 shows the postoperative improvement in $\mathrm{DH}$ and $\mathrm{DV}$.

\section{Discussion}

Facial reanimation is a complex and challenging field in reconstructive surgery. Various options are available for patients and it is important to provide patients with a dynamic treatment option. Free muscle transfer is the standard technique for long-standing facial paralysis ${ }^{5}$. Free muscle transfer can be completed as a single-stage or two-stage procedure wherein the muscle along with its nerve and vascular supply is taken and anastomosed at the affected side. The gracilis muscle is an ideal muscle for single stage transfer because it has a reliable vascular pedicle with a long nerve and can be easily harvested without functional loss. Because of the con- 
sistent segmental neurovascular anatomy, we harvested just the anterior one-third of the muscle as a separate motor unit, based on patient need which allowed us to avoid the excessive bulk. This approach also allows hemostasis before dividing the vascular pedicle and prevents hematoma formation. The nerve is usually coapted to the buccal branch of the facial nerve on the unaffected side, thus enabling a spontaneous symmetrical smile once the re-innervation is complete. This approach does involve a long waiting period, compared to the temporalis myoplasty, before the final results. Successful results depend on whether the free muscle transfer survives and depend on whether the muscle re-innervation is sufficient to generate a smile that is symmetrical with the healthy nonparalyzed side at rest and during smile. If the gracilis muscle re-innervation is insufficient, creating another cross facial nerve grafting and muscle transfer are then required. The free functioning muscle transfer technique can also be problematic due to flap failure, increased theatre time and cost. Preoperative and postoperative photos are shown in Fig. 5.

The lengthening temporalis myoplasty (LTM) approach was first described by Labbé in $1997^{6}$. LTM ensures the transfer of the temporalis muscle, which is innervated by the trigeminal nerve, to the upper lip without an interposition of aponeurotic tissue. Because of neural plasticity, the temporalis muscle changes its function by pulling the angle of the mouth upwards, along the vector of the contraction which produces a smile. The LTM approach is a dynamic treatment for longstanding facial paralysis. LTM surgery can be
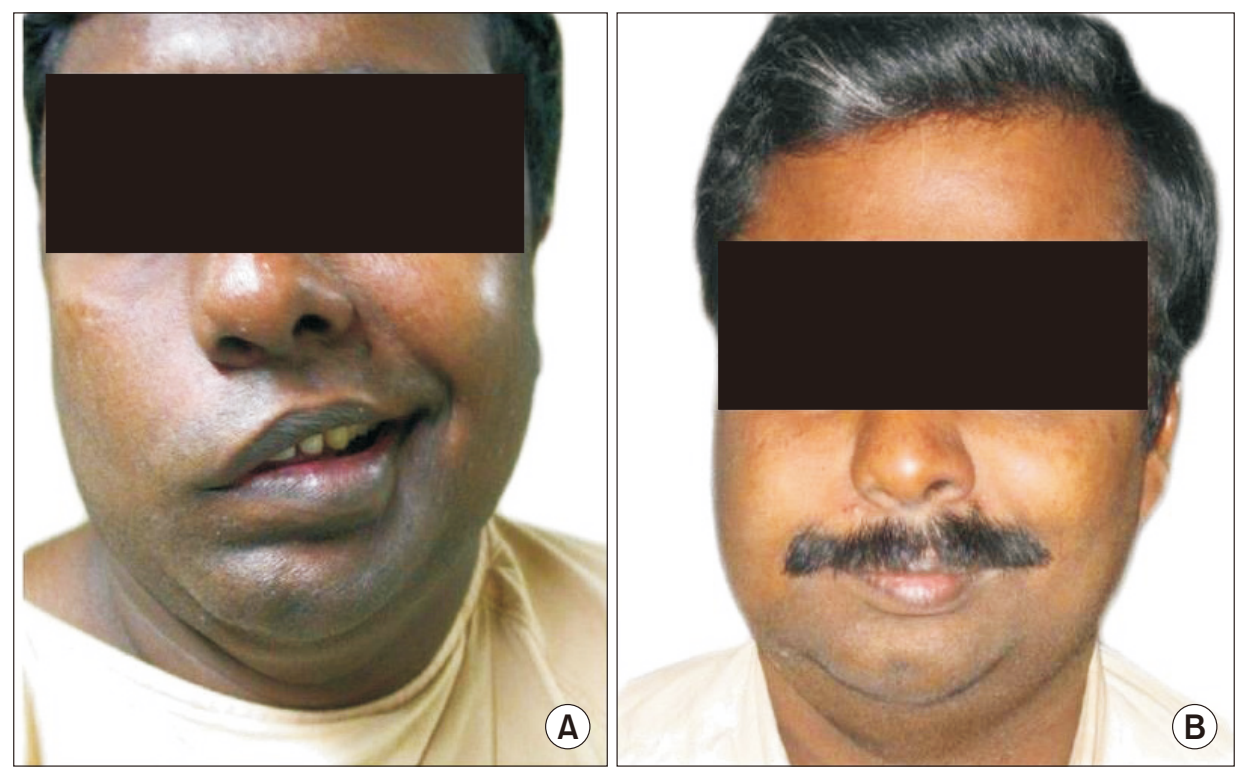

B)
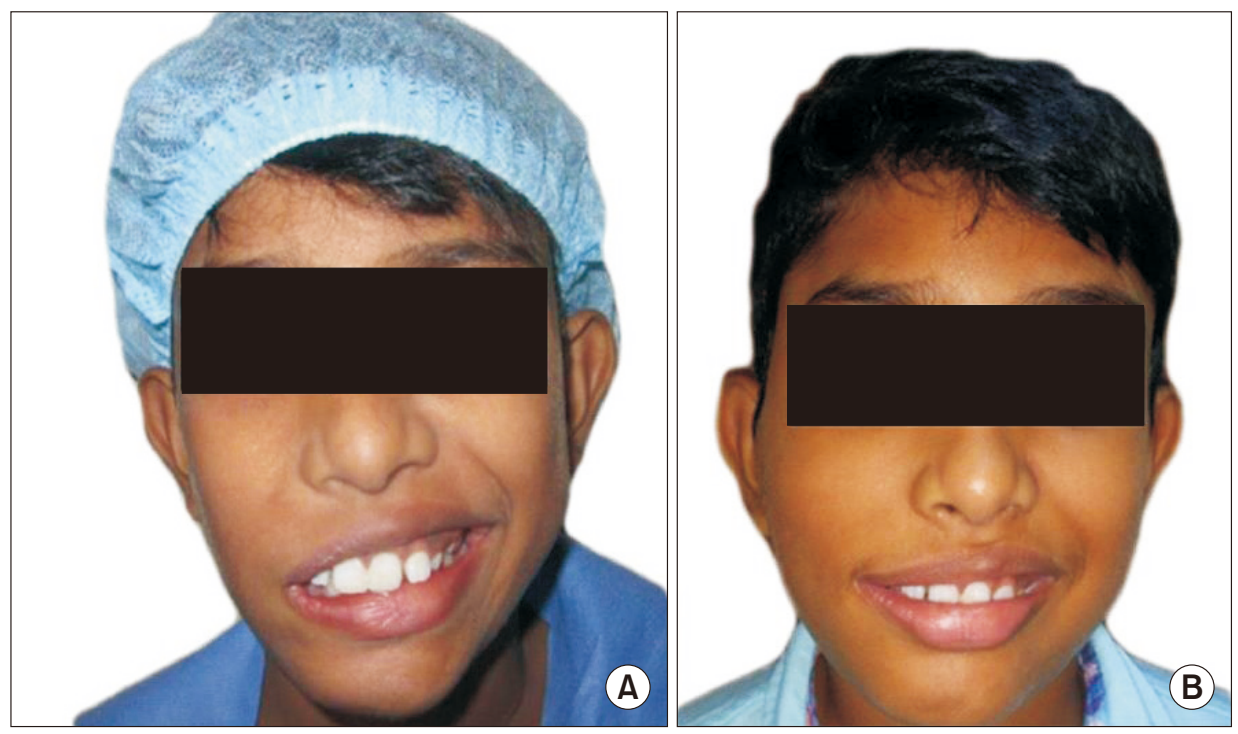

Fig. 6. Preoperativ (A) and one-year postoperative (B) images showing result of temporalis myoplasty.

Krishnakumar Krishnan Santha et al: Dynamic smile reanimation in facial nerve palsy. $J$ Korean Assoc Oral Maxillofac Surg 2020 

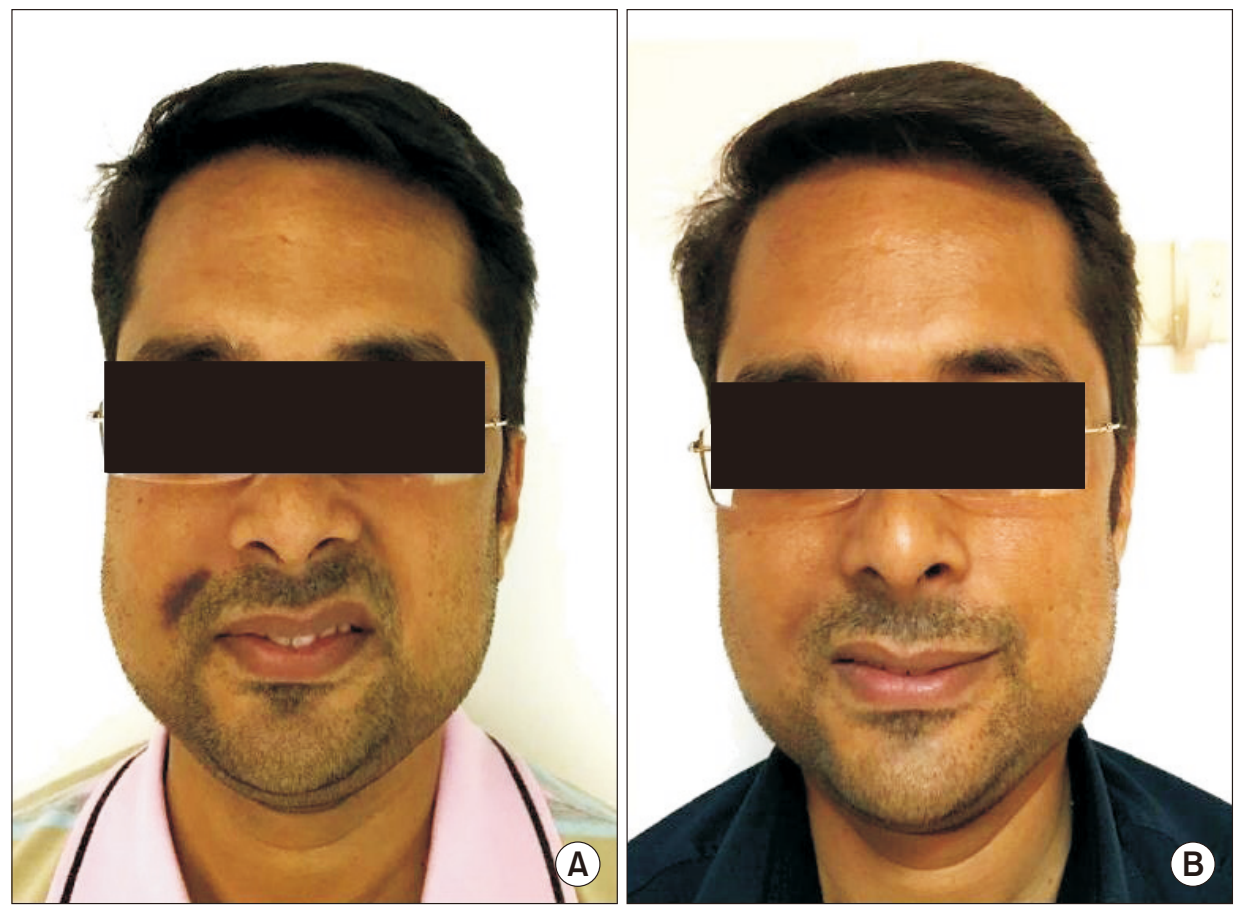

Fig. 7. A. Preoperative image showing synkinesis in left upper lip and nasolabial region. B. Postoperative image following botulinum toxin injection.

Krishnakumar Krishnan Santha et al: Dynamic smile reanimation in facial nerve palsy. $J$ Korean Assoc Oral Maxillofac Surg 2020

completed within one to two hours and similar results can be achieved, compared to free muscle transfer.(Fig. 6) However, even with this approach, it is nearly impossible for such patients to achieve a spontaneous smile.

Severe post-paralysis synkinesis can be managed easily with a nonsurgical method like botulinum toxin injection for selected muscles, and the injection produces local chemodenervation. Injection of botulinum toxin in healthy muscles increases the movements of paretic muscles secondary to a short-term reduction in the force of contraction of muscles on the normal side. An intramuscular injection of $2 \mathrm{IU}$ is given to the affected group of muscles in cases of synkinesis.(Fig. 7) Even though this approach requires repeat injections, it is minimally invasive and greatly improves facial symmetry ${ }^{7}$.

Improvement in both dimensions, i.e., vertically and horizontally, is essential for obtaining satisfactory results. Objective improvement alone may not always be associated with patient satisfaction, as the satisfaction is always subjective. However, subjective assessment alone does not quantify operative outcomes. Hence a combination of both subjective and objective assessments were used. In this series we found that facial reanimation procedures provided good facial symmetry and all patients were satisfied with the outcomes. (Table 2) Postoperative DH and DV values indicated great improvement and the analytical results indicated that the improvements were statistically significant. The role of nerve and muscle stimulation is crucial in the postoperative period, therefore, rehabilitation must be achieved for all patients. In our series we were able to assess outcomes in a small study group; however, the small patient population was a limitation, therefore, further studies are required in a large study group.

\section{Conclusion}

Even though free functioning muscle transfer is considered as the gold standard procedure, temporalis myoplasty is also a worthwhile option for patients with facial paralysis, as demonstrated in this series. Botulinum toxin can be confidently used before or after surgery or even as a single treatment modality in selected cases. Choosing the ideal procedure for patients is the most critical aspect for facial reanimation. Similar to other surgical procedures, postoperative rehabilitation therapy is also an essential component for achieving optimal outcomes.

\section{ORCID}

Krishnakumar Krishnan Santha, https://orcid.org/00000002-0526-8685

Subin Joseph, https://orcid.org/0000-0002-4079-5499

Sameer Latheef, https://orcid.org/0000-0002-3634-656X

Saju Narayanan, https://orcid.org/0000-0002-4937-8456

Santhy Mohanachandran Nair, https://orcid.org/0000-00023409-6923 
Bibilash Babu, https://orcid.org/0000-0003-0997-5448

Anand Sivadasan, https://orcid.org/0000-0003-3162-0037

Srivatsa Manjunath Shet, https://orcid.org/0000-0001-8494-8779

Rajesh Vardhan Pydi, https://orcid.org/0000-0002-6014-3375

Ajit Pati, https://orcid.org/0000-0002-4533-7534

Srikant Aruna Samantaray, https://orcid.org/0000-00025253-5096

\section{Authors' Contributions}

K.K.S. and S.J. conceptualized the study design. S.L., S.N., B.B., and A.P. did the literature search. S.J., S.M.N., and A.S. collected the data. S.J. and S.M.S. wrote the manuscript and statistical analysis. R.V.P. and S.A.S. did proof reading and bibliography check. S.J. and S.M.S. coordinated and prepared final draft. All authors read and approved the final manuscript.

\section{Acknowledgements}

The authors would like to thank Mrs. Shamna, the Department Secretary, and Mr. Vinod the operating room technician for their technical help and illustration of figures.

\section{Ethics Approval and Consent to Participate}

This study was approved by the Institutional Ethics Committee of Baby Memorial Hospital (No. BMH/IEC/ $\mathrm{PS} / 09 / 2020$ ), and the informed consent was waived.

\section{Consent for Publishing Photographs}

Written informed consent was obtained from the patients for publication of this article and accompanying images.

\section{Conflict of Interest}

No potential conflict of interest relevant to this article was reported.

\section{References}

1. Nduka C, Hallam MJ, Labbe D. Refinements in smile reanimation: 10-year experience with the lengthening Temporalis Myoplasty. J Plast Reconstr Aesthet Surg 2012;65:851-6.

2. Ghali S, MacQuillan A, Grobbelaar AO. Reanimation of the middle and lower face in facial paralysis: review of the literature and personal approach. J Plast Reconstr Aesthet Surg 2011;64:423-31.

3. Kumar PA. Cross-face reanimation of the paralysed face, with a single stage microneurovascular gracilis transfer without nerve graft: a preliminary report. Br J Plast Surg 1995;48:83-8.

4. Niziol R, Henry FP, Leckenby JI, Grobbelaar AO. Is there an ideal outcome scoring system for facial reanimation surgery? A review of current methods and suggestions for future publications. J Plast Reconstr Aesthet Surg 2015;68:447-56.

5. Sforza C, Frigerio A, Mapelli A, Tarabbia F, Annoni I, Colombo $\mathrm{V}$, et al. Double-powered free gracilis muscle transfer for smile reanimation: a longitudinal optoelectronic study. J Plast Reconstr Aesthet Surg 2015;68:930-9.

6. Labbé D. [Lengthening of temporalis myoplasty and reanimation of lips. Technical notes]. Ann Chir Plast Esthet 1997;42:44-7. French.

7. Salles AG, Toledo PN, Ferreira MC. Botulinum toxin injection in long-standing facial paralysis patients: improvement of facial symmetry observed up to 6 months. Aesthetic Plast Surg 2009;33:58290.

8. Sassoon EM, Poole MD, Rushworth G. Reanimation for facial palsy using gracilis muscle grafts. Br J Plast Surg 1991;44:195200.

9. Venkataraman A, Mardi SK, Pillai S. Comparison of Eyemetrics and Orbscan automated method to determine horizontal corneal diameter. Indian J Ophthalmol 2010;58:219-22.

10. Panciera DT, Sampieri C, Deganello A, Danesi G. Lengthening temporalis myoplasty: objective outcomes and site-specific qualityof-life assessment. Otolaryngol Head Neck Surg 2017;157:966-72.

11. Foirest C, Granger B, Gatignol P, Bernat I, Nguyen Y, Lamas G, et al. Smile reanimation after unilateral facial palsy by lengthening temporalis myoplasty: objective and subjective evaluation on 25 cases. Plast Reconstr Surg 2017;139:984e-93e.

How to cite this article: Krishnan Santha K, Joseph S, Latheef S, Narayanan S, Nair SM, Babu B, et al. Dynamic smile reanimation in facial nerve palsy. J Korean Assoc Oral Maxillofac Surg 2020;46:143-149. https://doi.org/10.5125/jkaoms.2020.46.2.143 